\title{
TOWARD A CONCEPTUAL MODEL FOR UNDERSTANDING THE RELATIONSHIPS AMONG MMORPGS, GAMERS, AND ADD-ONS
}

\author{
Qiunan Zhang, University of Memphis, qzhang4@memphis.edu \\ Yuelin Zhu, University of Memphis, yzhu6@memphis.edu \\ Colin G. Onita, San Jose State University, colin.onita@sjsu.edu \\ M. Shane Banks, University of North Alabama, mbanks@una.edu \\ Xihui Zhang, University of North Alabama, xzhang6@una.edu
}

\begin{abstract}
The consumption of video games has become a significant economic, cultural, and entertainment phenomenon worldwide. Massively Multiplayer Online Role Playing Games (MMORPGs) are an important category of such games. In MMORPGs, gamers often play with add-ons to enhance their gaming experience. In previous research studies on MMORPGs, few of them have focused on the relationships among MMORPGs, gamers, and add-ons. This study presents a conceptual framework for use in addressing the following two questions: (1) What is the relationship between gamers and add-ons in MMORPGs? (2) How do factors (such as game quality and updates) impact gamers and add-ons and the relationship between them? In this paper, we develop a research model and describe a quantitative methodology that can be used to test and investigate the above questions. Implications for research and practice, as well as limitations and future research directions, are discussed.
\end{abstract}

Keywords: MMORPGs, Motivations for Gaming, Gamers, Add-ons, Game Quality, Game Updates, Software Platform

\section{INTRODUCTION}

In 2017, video games became the most popular and profitable form of entertainment, producing an estimated revenue of \$116 billion eclipsing TV and TV streaming services' revenue of \$105 billion (D’Argenio, 2018). The consumption of video games has become a significant economic, cultural, and entertainment phenomenon worldwide (Marchand \& Hennig-Thurau, 2013). According to a recent report from Newzoo.com, there are 2.3 billion gamers across the globe who spent approximately $\$ 137.9$ billion on games in 2018 (Wijman, 2018). Being an important category of video games, Massively Multiplayer Online Role Playing Games (hereafter MMORPGs) have already drawn significant attention from academia (e.g., Martin \& Steinkuehler, 2010; Sourmelis et al., 2017). MMORPGs are designed to promote sociability, communication, and collaboration amongst players pursuing shared missions or quests in a prescribed gaming environment (Yu, 2009).

"A video game is an electronic game that involves interaction with a user interface to generate visual feedback on a two- or three-dimensional video display device such as a touchscreen, virtual reality headset or monitor/TV set" ("Video game," 2020, para. 1). "Massively multiplayer online role-playing games (MMORPGs) are persistent, online gaming worlds that feature dynamic opportunities for virtual social interaction” (Hopp et al., 2015, p. 468). MMORPGs are regarded as a digital game-based platform (Wu et al., 2014). The motivations for gamers to play online games have been studied in prior research, and the results indicate that there are three key components that drive gamers to play online games: an achievement component, a social component, and an immersion component (Agarwal \& Karahanna, 2000; Hsu \& Lu 2004; van der Heijden, 2004; Yee, 2006).

MMORPGs require players to synthesize, analyze, and evaluate information, apply critical thinking, and solve problems. Thus, MMORPGs are also considered as learning environments that support players while they are playing games (Dickey, 2007; Dickey, 2011; Martin \& Steinkuehler, 2010; Susaeta et al., 2010). Driven by the desire to acquire more power, knowledge, and gaming skills (Bennerstedt et al., 2012; Liu, 2015; McCreery et al., 2011), some players use external resources to develop programs of "mods" or "add-ons" that can be used to alter the game's interfaces for improved gaming experience (Golub, 2010). Some add-ons are developed by players to help get additional information from the Application Programming Interface (API), and other add-ons are design to improve 


\section{Issues in Information Systems \\ Volume 21, Issue 2, pp. 186-195, 2020}

gaming interfaces. Figure 1 shows two sets of screenshots in the same MMORPGs: one set with add-ons and the other without add-ons. With add-ons, game user interfaces are elegant and convenient. As such, gamers can more easily (1) find what they need from their packages; (2) identify the situations when to use gold and other materials; and (3) recognize other gamers' guild, major, talent, equipment level, realm, and other information. It is generally agreed upon that add-ons can enhance gamers' gaming experience in terms of the achievement component, social component, and immersion component. Add-ons can be regarded as a type of third-party applications (TPAs), since TPAs are developed based on the platform, and the purpose of TPAs is to satisfy the end-users' needs of the platform (Ghazawneh \& Henfridsson, 2013). In general, the companies of MMORPGs need to decide what kinds of add-ons could be used in the game. For instance, the company will likely forbid some add-ons that can harm the mechanics of the game or can be against fair game rules.

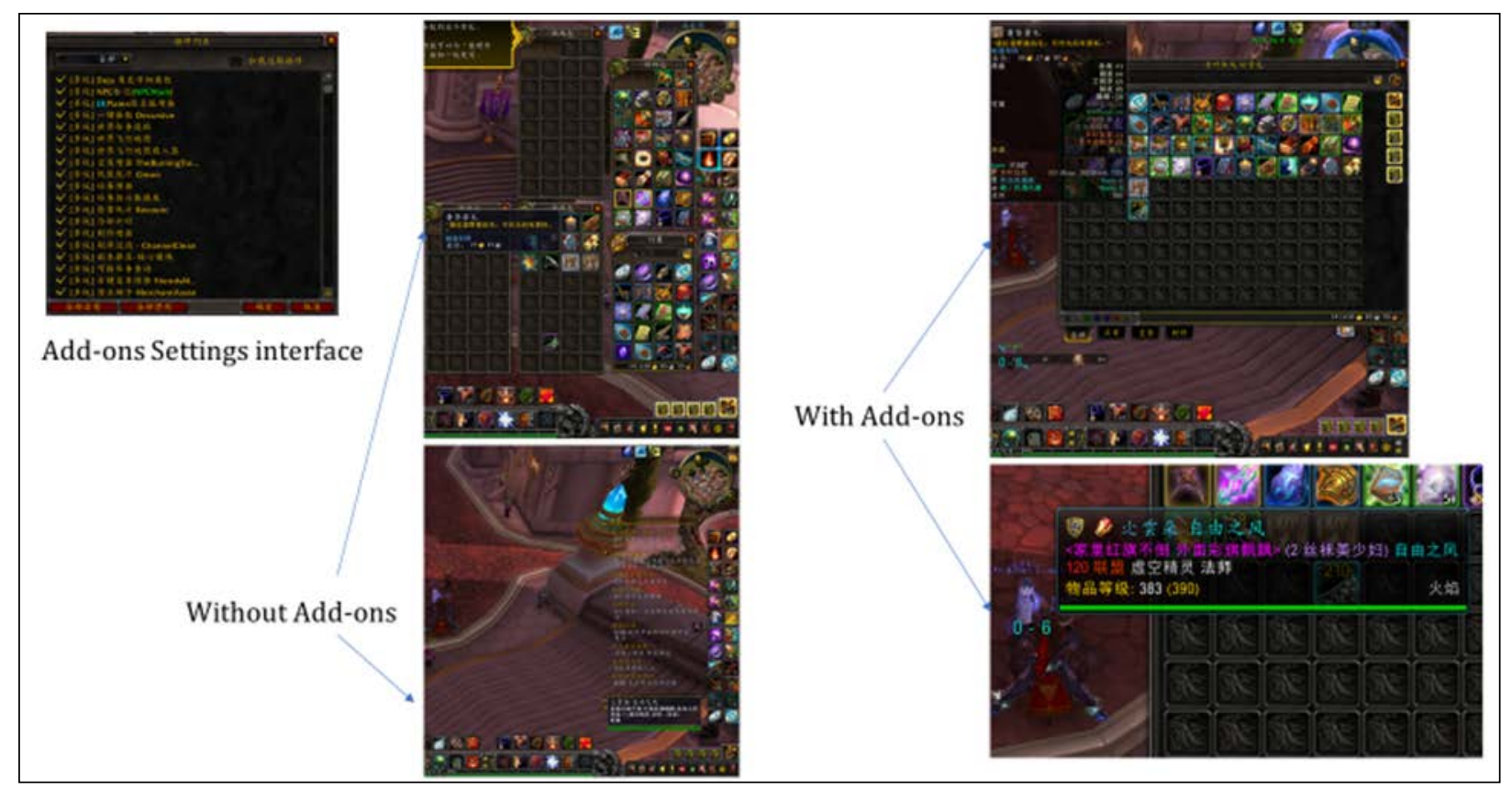

Figure 1. Examples of Add-ons in World of Warcraft

Since MMORPGs can be regarded as a digital game-based platform (Wu et al., 2014), and add-ons can be regarded as TPAs, the relationships among MMORPGs, gamers, and add-ons are similar to the relationships among platform, users, and TPAs. Add-ons are becoming more and more important, and in some cases, they seem indispensable to gamers. This is very important to game companies and researchers, because the number and diversity of add-ons could influence gamers' behaviors and thought processes. Although there has been significant research on MMORPGs in past the 10 years, few studies have focused on the effect of add-ons or examined the network effects or cross network effects among gamers. To address this research gap, this study presents a conceptual framework for use in addressing the following two questions: (1) What is the relationship between gamers and add-ons in MMORPGs? (2) How do factors (such as game quality and updates) impact gamers and add-ons and the relationship between them? Most of the research studies on MMORPGs are qualitative, and more quantitative studies are needed (Sourmelis et al., 2017). Therefore, we develop a research model and describe a quantitative methodology that can be used to test and investigate the research questions.

\section{LITERATURE REVIEW}

Given that this research aims to study the relationships among gamers, MMORPGs, and add-ons, the reasons why gamers play MMORPGs are very important. Yee (2006) summarized 10 motivation subcomponents and grouped them into three overarching components: achievement, social, and immersion. The achievement component has three subcomponents: advancement (the desire to gain power, progress rapidly, and accumulate in-game symbols of wealth 


\section{Issues in Information Systems \\ Volume 21, Issue 2, pp. 186-195, 2020}

or status), mechanics (having an interest in analyzing the underlying rules and systems in order to optimize character performance), and competition (the desire to challenge and compete with others). The social component also has three subcomponents: socializing and critical mass (having an interest in helping and chatting with other players), relationship (the desire to form long-term meaningful relationships with others), and teamwork (deriving satisfaction from being part of a group effort) (Hsu \& Lu, 2004). The immersion, also described as flow (Agarwal \& Karahanna, 2000; Hsu \& Lu, 2004), component has four subcomponents: discovery (finding and knowing things that most other players do not know about), role-playing (creating a person with a background story and interacting with other players to create an improvised story), customization (having an interest in customizing the appearance of their character), and escapism (using the online environment to avoid thinking about real life problems). If MMORPGs meet these 10 motivation subcomponents, it is very likely the MMORPGs will attract gamers to play.

Since MMORPGs can be regarded as a digital game-based platform (Wu et al., 2014), reviewing the literature pertaining to the platform ecosystem can provide a theoretical structure or model which can help in explaining the relationships among gamers, MMORPGs, and add-ons. The extant literature has categorized platforms into four broad types: exchanges, advertising-supported media, transaction systems, and hardware/software platforms (Sriram et al., 2015). Although the relationship between seller-side and buyer-side in C2C exchange platforms is positive (Chu \& Manchanda, 2016), the relationship between viewers and advertisers in TV networks is not just simply positive. More viewers will attract more advertisers; on the contrast, more advertisers will have negative effects on viewers (Wilbur, 2008). For the hardware/software platform, there are asymmetric Cross Network Effects (CNEs) between different users in a specific platform (Song et al., 2018), and governance of the software platform such as updates and review policy can affect the relationship between users and apps. At the same time, there are conflicts that exist between TPAs development and platform governance and maintenance. The TPAs development may have different goals than those of platform governance and maintenance, since platform governance and maintenance aim to control the TPAs, improve the platform performance, and design effective architectures (Ghazawneh \& Henfridsson, 2013).

According to the literature, there may exist some CNEs or other relationships among gamers, MMORPGs, and addons when we consider MMORPGs as a software platform and add-ons as TPAs in the sense that there may be a cocreation (Banks et al., 2013) effect between all the actors on the MMORPG platform that provides additional value to actors. The actors relevant to a MMORPG platform are the platform (game) developer, TPAs, and the gamers themselves. Through their interaction, the MMORPG gains value in use that depends on the harmonious meeting of interests and motivations of the platform actors (Banks et al., 2013). Based on our review of the literature and the lack of research on the relationships among the gamers, MMORPGs, and add-ons, we develop a theoretical model and propose a list of hypotheses to explain and test the relationships among gamers, MMORPGs, and add-ons in the following sections.

\section{RESEARCH MODEL AND DEVELOPMENT OF HYPOTHESES}

MMORPGs are designed with deep understanding of gamer needs (Jung et al., 2014). As mentioned in previous sections, the three components of gamer motivation are achievement, social, and immersion (Agarwal \& Karahanna, 2000; Hsu \& Lu, 2003; Yee 2006). Therefore, gamers' needs can be explained as achievement needs, social needs, and immersion needs. Add-ons help gamers get and analyze information, provide a way for enhanced party communication, provide more attractive and convenient user interfaces, as well as improved graphics performance. Platform updates are an important way for the platform managers to address governance by improving the platform's design and architecture (Tiwana, 2014). Game platforms are expected to be updated continuously to improve game design, user interfaces, and story background.

\section{Gamers and MMORPGs Quality}

In this research, the degree of how a MMORPG meets gamers' needs can be regarded as MMORPG quality. Good quality MMORPGs are typically more attractive to gamers, since gamers want to play games designed with a deep understanding of their needs (Jung et al., 2014). High-quality MMORPGs will attract more gamers than low-quality MMORPGs as indicated by a larger number of gamers using the platform. There are several well-respected game review websites that score games on aspects such as story, operation, and video graphics. In this research, game quality will be measured by game quality scores from those game review websites. Based on this argument, the higher quality score, the more gamers will be attracted to the game resulting in a higher gamer population. Thus, hypothesis 1 is: 
$\mathrm{H}_{1}$ : MMORPGs game quality has a positive effect on gamer population.

\section{Gamers and Add-ons}

In the context of software platforms, the growth of the user base helps the platform motivate more third-party app development, and the growth of the app base helps the platform attract more users. TPA developers find the software platform a more valuable place to participate when there are more platform users (Banks et al., 2013; Song et al., 2018). As aforementioned, MMORPGs can be regarded as a digital game-based platform, gamers of MMORPGs can be regarded as the users of MMORPGs, and add-ons can be regarded as TPAs. Network effects result in increased gamer population, and the number and diversity of add-ons may also increase. As such, more gamers in a MMORPG will attract more add-on developers to develop more and diversified add-ons. In addition, some add-ons are developed by the gamers themselves to improve their gaming experience. These gamer-developed add-ons improve the experience of other gamers and help attract additional gamers to the platform. As more gamers interact with the MMORPG it leads to a higher number and increased diversity of add-ons in MMORPGs. In this study, we define the level of diversity and number of add-ons as "add-on volume." Thus, we posit:

$\mathrm{H}_{2}$ : Gamer population has a positive effect on add-on volume.

Although the gamer population size may have positive effect on add-on volume (number and diversity), higher addon volume does not seem to attract more gamers to join in MMORPGs. As such, we maintain that no cross-network effects exist in MMORPGs among MMORPGs, gamers, and add-ons.

\section{Effect of Add-ons on the Relationship of Gamers and MMORPGs Quality}

MMORPGs require gamers to synthesize, analyze, and evaluate information, apply critical thinking, and solve problems in the games (Dickey, 2007; Dickey, 2011; Susaeta et al., 2010). Add-ons can be regarded as tools to help gamers perform these tasks. From a technology acceptance model (TAM) aspect (Davis, 1989), good MMORPGs can provide "usefulness" for gamers, and add-ons can provide "ease-of-use" for gamers; from the service comprehensiveness aspect (Zhang et al., 2016), add-ons can provide "convenience" for gamers. In these ways, addons can help gamers obtain a higher level of "usefulness" and fulfill their needs more easily in MMORPGs. The actors on the MMORPG platform are therefore co-creating the value in use of the platform and, therefore, the add-ons can enhance game quality. Based on this argument, hypothesis 3 is:

$\mathrm{H}_{3}$ : Higher add-on volume strengthens the effect of MMORPGs game quality on gamer population.

\section{MMORPGs Governance and MMORPGs Quality}

Platform (game) updates are an important way for platform managers to address governance by improving the platform's design and architecture (Tiwana, 2014). Platform updates often need to update both the app-side and the user-side to make adaptive actions such as conforming to changing APIs and addressing compatibility issues (Song et al., 2018). Frequent updates suggest that the platform is constantly improved and adapted to the changing environment by fixing issues and incorporating advanced features (Arora et al., 2006). New versions of MMORPGs generally mean significant improvement or substantial changes in game content and mechanisms, not only bug-fixes. Significant updates are recorded with patch numbers, and the game quality score will be re-evaluated by game review websites after the update. For every new version update, the details of the update are posted on the MMORPGs website. In most cases, the updates include improvement on game architecture, mechanisms, graphics, user interface, and bugfixes. Generally, those improvements help fulfil gamers' needs which were not fulfilled in previous versions. Thus, hypothesis 4 is:

$\mathrm{H}_{4}$ : MMORPGs game updates improve MMORPGs game quality. 


\section{Effect of MMORPGs Governance on Relationship of Gamers and Add-ons}

The goals of maintaining platform control by platform owners are different from those of the third-party application developers, and these differences could lead to conflict between the platform and TPAs (Ghazawneh \& Henfridsson, 2013). In addition, there may be conflict between add-ons and MMORPGs updates. Updates of a MMORPG may change the game design, user interface, and/or architecture leading to incompatibility with existing add-ons. Gamers may not be able to use these add-ons following an update leading to a negative playing experience. Some gamers may not join the game after a new version update while they wait for the completion of add-on updates. Thus, version updates will have a negative effect on add-ons used by gamers, and gamer population may be influenced by this negative effect. Based on the above statements, hypothesis 5 is as follows:

$\mathrm{H}_{5}$ : In the short term, MMORPGs game updates weaken the effect of add-on volume on the relationship between MMORPGs game quality and gamer population.

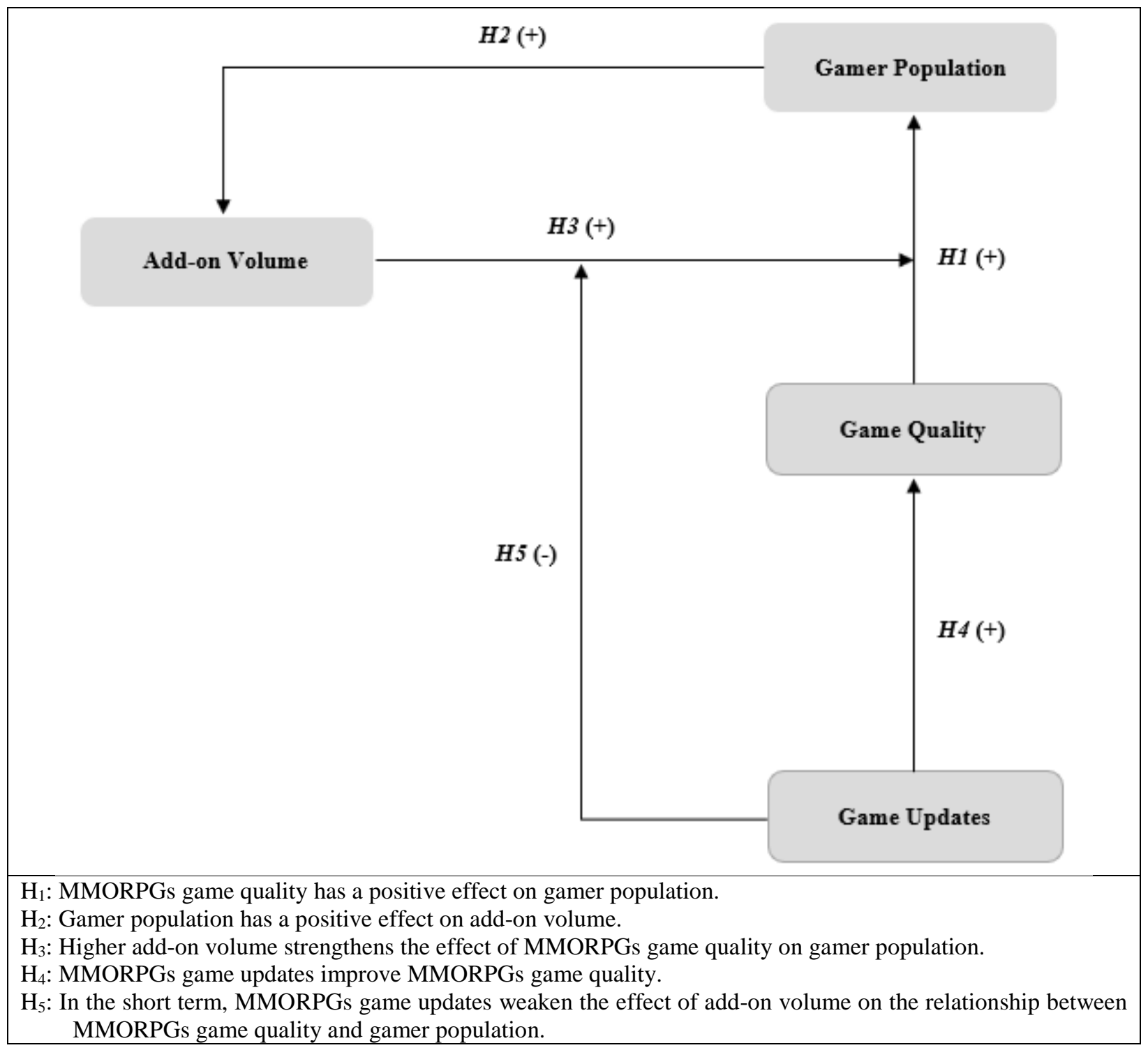

Figure 2. The Research Model and Hypotheses 


\section{Issues in Information Systems}

Volume 21, Issue 2, pp. 186-195, 2020

\section{METHODOLOGY}

\section{Research Context}

We focused on three primary attributes to help identify MMORPGs that were most appropriate for investigating our research questions: popularity in terms of total users, sufficient maturity in terms of time from initial release, and the total number of game updates which indicates a commitment to maintenance of the game platform. Based on these criteria we selected World of Warcraft (released in 2004), Final Fantasy online (released in 2010), and Guild Wars (released in 2005). These MMORPGs are the top three in terms of gamer population in the U.S., have been in use for at least ten years, and have had a large number of updates since initial release.

\section{Measurements}

In this research, the gamer population (or player population) can be collected from the MMORPGs official website and other game statistics sites. After a new version update, a rating score will usually be given to the new version update. Figures 3 and 4 show IGN and Gamespot ratings for World of Warcraft (WOW), respectively.

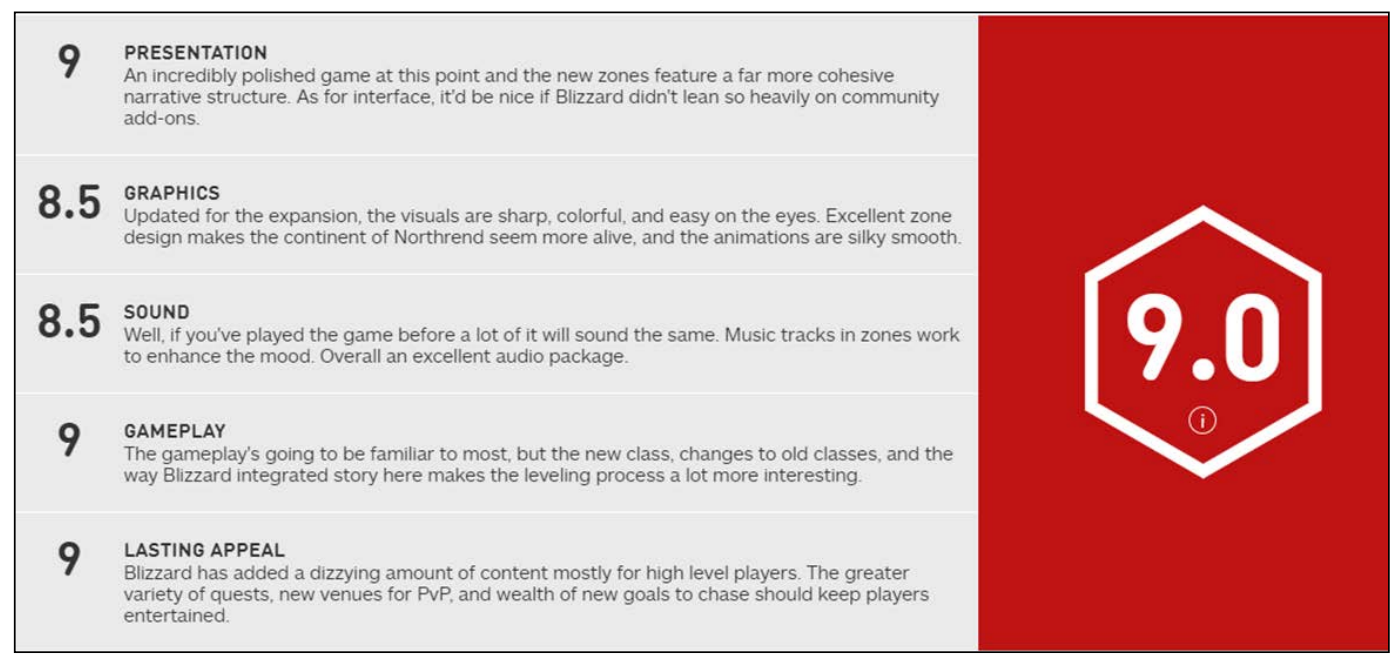

Figure 3. IGN Rating on WOW: Wrath of Lich King

\section{World of Warcraft / $\mathrm{PC}$}

THE GOOD

$\oplus$ Huge, beautiful, seamless world

๑ High streamlined and conducive to short or long play

sessions

$\oplus$ Exciting, action-packed combat

$\oplus$ Elegant, easy-to-use interface

$\oplus$ Excellent music and sound

\section{Other Platform Reviews for World of Warcraft}

(3) 7 PC / World of Warcraft: Battle For Azeroth - Come One, Come All Read Review

PC / World of Warcraft: Warlords of Draenor Read Review

Figure 4. Gamespot Rating on WOW

In this research, game quality will be measured by game rating scores from a set of game review websites. Generally, game quality is measured by the game presentation, graphics, sound, gameplay, and lasting appeal. Gaming experts assess the games for the review websites when a new game is released and after major updates to the gaming platform. 
In this research we plan to use IGN and Gamespot as our main sources of game review websites to collect the game quality scores for the three games. The number and diversity of add-ons will be measured by the volume of add-ons available through the official add-on and fan add-on websites for the MMORPG.

MMORPGs new version updates will be measured by the frequency of MMORPGs version updates in a fixed time period. For MMORPGs, every new version update will be posted on the official websites with version updates number and/or patch notes. Data on the frequency of version updates of MMORPGs in a fixed time period (e.g., from 2008 to 2020) can be collected.

\section{Econometrics Estimation}

In this study, the most important component is to prove the causal relationship between constructs during a specific time period. MMORPGs are the research context in this study, and in order to investigate the research model, a longitudinal data gathering method is the most appropriate.

This research will adopt a vector autoregression with exogenous variable (VARX) time-series and cross-sectional analysis technique (Dekimpe \& Hanssens, 1999; Luo, 2009; Pauwels, 2004; Song et al., 2018). VARX models (as shown below) can simultaneously capture the dynamic and intricate mutual influences among different variables.

$$
Y_{t}=a_{0}+A_{1} Y_{t-1}+\cdots+A_{p} Y_{t-p}+B_{1} X_{t-1}+\cdots+B_{q} X_{t-q}+U_{t}
$$

Where $Y_{t} \in R_{k}, X_{t} \in R_{m}$ is a vector of exogenous variables, $a_{0}$ is a vector of intercepts, the $A_{j}$ 's are $k * k$ coefficient matrices, the $B_{i}$ 's are $k^{*} m$ coefficient matrices, and $U_{t} \in R_{k}$ is the vector of errors. Figure 5 shows the specific equation that can be used in this research:

$$
\begin{aligned}
& {\left[\begin{array}{c}
G Q_{t} \\
G P_{t} \\
G U_{t} \\
A V_{t} \\
G Q_{t} \times A V_{t} \\
G U_{t} \times\left(G Q_{t} \times A V_{t}\right)
\end{array}\right]=a_{0}+\left[\begin{array}{ccc}
A_{G Q_{1}} & \cdots & A_{G Q_{p}} \\
A_{G P_{1}} & \cdots & A_{G P_{p}} \\
A_{G U_{1}} & \cdots & A_{G U_{p}} \\
A_{A V_{1}} & \cdots & A_{A V_{p}} \\
A_{G Q_{1} \times A V_{1}} & \cdots & A_{G Q_{p} \times A V_{p}} \\
A_{G U_{1} \times\left(G Q_{1} \times A V_{1}\right)} & \cdots & A_{G U_{p} \times\left(G Q_{p} \times A V_{p}\right)}
\end{array}\right] \times} \\
& {\left[\begin{array}{ccc}
G Q_{t-1} & \cdots & G Q_{t-p} \\
G P_{t-1} & \cdots & G P_{t-p} \\
G U_{t-1} & \cdots & G U_{t-p} \\
A V_{t-1} & \cdots & A V_{t-p} \\
G Q_{t-1} \times A V_{t-1} & \cdots & G Q_{t-p} \times A V_{t-p} \\
G U_{t-1} \times\left(G Q_{t-1} \times A V_{t-1}\right) & \cdots & G U_{t-p} \times\left(G Q_{t-p} \times A V_{t-p}\right)
\end{array}\right]+\left[\begin{array}{ccc}
B_{G Q_{1}} & \cdots & B_{G Q_{q}} \\
B_{G P_{1}} & \cdots & B_{G P_{q}} \\
B_{G U_{1}} & \cdots & B_{G U_{q}} \\
B_{A V_{1}} & \cdots & B_{A V_{q}} \\
B_{G Q_{1} \times A V_{1}} & \cdots & B_{G Q_{q} \times A V_{q}} \\
B_{G U_{1} \times\left(G Q_{1} \times A V_{1}\right)} & \cdots & B_{G U_{q} \times\left(G Q_{q} \times A V_{q}\right)}
\end{array}\right] \times} \\
& {\left[\begin{array}{ccc}
G Q_{t-1} & \cdots & G Q_{t-q} \\
G P_{t-1} & \cdots & G P_{t-q} \\
G U_{t-1} & \cdots & G U_{t-q} \\
A V_{t-1} & \cdots & A V_{t-q} \\
G Q_{t-1} \times A V_{t-1} & \cdots & G Q_{t-q} \times A V_{t-q} \\
G U_{t-1} \times\left(G Q_{t-1} \times A V_{t-1}\right) & \cdots & G U_{t-q} \times\left(G Q_{t-q} \times A V_{t-q}\right)
\end{array}\right]+U_{t}}
\end{aligned}
$$

Figure 5. The Specific Equation to Be Used

Where GQ, GP, GU, and AV stand for game quality, gamer population, game updates, and add-on volume, respectively; t, p, and q represent different time periods. Axx ${ }^{\text {'s }}$ are coefficient matrices, B $\mathrm{xx}_{\mathrm{i}}$ 's are coefficient matrices for exogenous variables, and $U_{t}$ is the vector of errors. 


\section{Issues in Information Systems \\ Volume 21, Issue 2, pp. 186-195, 2020}

Vector-auto-regression (VAR) is a stochastic process model used to capture the linear interdependencies among multiple time series. Each variable has an equation explaining its evolution based on its own lagged values, the lagged values of the other model variables, and an error term. The only prior knowledge required is a list of variables which can be hypothesized to affect each other inter-temporally. VARX model is basically VAR model with exogenous variables. For example, the VARX model could capture how game quality influences gamer population in a specific time period (e.g., half year or three months). Through the Granger causality test, the causal effect can be identified among these constructs; for instance, during a specific time period, increasing game quality may cause an increase in gamer population, and increasing gamer population is the reason for increasing add-on volume.

\section{DISCUSSION}

\section{Summary of Content}

In this research, we developed a conceptual model for understanding the relationships among MMORPGs, gamers, and add-ons. Higher MMORPGs game quality will attract more gamers to play the game, and more gamers in MMORPGs will result in more add-ons and higher level of add-on diversity. However, the add-on number and diversity will not increase continually after gamers' needs are saturated. Also, higher level diversity and more addons will strengthen the effect of the MMORPGs game quality on gamer population. New version updates will improve MMORPGs game quality, but weaken the effect of add-ons on the relationship between MMORPGs quality and gamer population in the short term.

\section{Research Implications}

MMORPGs are digital based platforms, however, CNEs are not evident in these platforms. In general, gamers do not play a MMORPG just because the game has great add-ons. Add-ons are tools to assist the gamers to get a better gaming experience, but add-ons alone cannot attract gamers to play games without the help of a quality MMORPG. This is because the value of a MMORPG is realized through value-in-use by all the actors that activate on the MMORPG platform and co-create their experience and the value of the MMORPG platform (Banks et al., 2013). In this research, we investigate the effect of add-ons on the relationship between gamers and MMORPGs. There is a lack of research that examines how add-ons impact this relationship in MMORPGs or in other digital-based platforms. This is the important difference between this research and other extant research studies that focus on CNEs in platforms.

\section{Practical Implications}

The results of this research will provide some insights for game companies on how to handle add-ons in their games. MMORPGs companies and developers should pay more attention to add-on management. Data concerning add-ons can provide useful information to help better understand gamers' needs. From the service comprehensive aspect (Zhang et al., 2016), game companies may not need to manage add-ons so strictly since add-ons could help gamers get more convenience when they play games. In the real world, game companies cannot develop a comprehensive set of features and user interfaces to satisfy all gamers. However, gamers could combine different types of add-ons to come up with their own "build," thus saving game companies resources and time by allowing the MMORPG user to co-create the game.

\section{Limitations and Future Research}

Our research has three limitations. First, game updates may not be the only factor influencing game quality; some specific settings of the game may have impact on game quality as well (e.g., the story background). Second, the game quality evaluation is a very subjective process and may not reflect the actual game quality. For many gamers, the game is not only a software, but also an artwork. Third, add-ons may have different effects on new gamers and experienced gamers; as a result, new gamers and experienced gamers may have different attitudes to add-ons.

Future studies will attempt to investigate the proposed conceptual model by collecting the data specified in this paper. The model can be empirically validated by using the econometrics estimation method to identify and confirm the casual relationships among the major constructs in the proposed conceptual model. To address the above limitations, 


\section{Issues in Information Systems}

Volume 21, Issue 2, pp. 186-195, 2020

our future research will attempt to identify other factors which may influence game quality through more cases and investigations. As for the effect of add-ons on different types of gamers, we plan to analyze different (new/experienced) gamers to investigate whether there are differences between the gamers along these dimensions. Also, future research can focus on how gamer behavior influences game updates and add-on volume. Ultimately, the aim of the game and add-ons is to serve gamers and satisfy their needs.

\section{REFERENCES}

Agarwal, R., \& Karahanna, E. (2000). Time flies when you're having fun: Cognitive absorption and beliefs about information technology usage. MIS Quarterly, 24(4), 665-694.

Arora, A., Caulkins, J. P., \& Telang, R. (2006). Sell first, fix later: Impact of patching on software quality. Management Science, 52(3), 465-471.

Banks, M. S., Onita, C. G., \& Kettinger, W. J. (2013). IT enabled co-creation platforms: Tapping the power of the prosumer. Journal of Information Technology Management, 24(1), 49-58.

Bennerstedt, U., Ivarsson, J., \& Linderoth, J. (2012). How gamers manage aggression: Situating skills in collaborative computer games. International Journal of Computer-Supported Collaborative Learning, 7(1), 43-61.

Chu, J., \& Manchanda, P. (2016). Quantifying cross and direct network effects in online consumer-to-consumer platforms. Marketing Science, 35(6), 870-893.

D’Argenio, A. M. (2018, July 10). Statistically, video games are now the most popular and profitable form of entertainment. Retrieved from https://www.gamecrate.com/statistically-video-games-are-now-mostpopular-and-profitable-form-entertainment/20087

Dekimpe, M. G., \& Hanssens, D. M. (1999). Sustained spending and persistent response: A new look at long-term marketing profitability. Journal of Marketing Research, 36(4), 397-412.

Dickey, M. D. (2007). Game design and learning: A conjectural analysis of how massively multiple online roleplaying games (MMORPGs) foster intrinsic motivation. Educational Technology Research and Development, 55(3), 253-273.

Dickey, M. D. (2011). World of Warcraft and the impact of game culture and play in an undergraduate game design course. Computers \& Education, 56(1), 200-209.

Ghazawneh, A., \& Henfridsson, O. (2013). Balancing platform control and external contribution in third-party development: The boundary resource model. Information Systems Journal, 23(2), 173-192.

Golub, A. (2010). Being in the world (of warcraft): Raiding, realism, and knowledge production in a massively multiplayer online game. Anthropological Quarterly, 83(1), 17-45.

Hopp, T., Barker, V., \& Weiss, A. S. (2015). Interdependent self-construal, self-efficacy, and community involvement as predictors of perceived knowledge gain among MMORPG players. Cyberpsychology, Behavior, and Social Networking, 18(8), 468-473.

Hsu, C.-L., \& Lu, H.-P. (2004). Why do people play on-line games? An extended TAM with social influences and flow experience. Information \& Management, 41(7), 853-868.

Jung, H. S., Kim, K. H., \& Lee, C. H. (2014). Influences of perceived product innovation upon usage behavior for MMORPG: Product capability, technology capability, and user centered design. Journal of Business Research, 67(10), 2171-2178. 
Liu, K.-Y. (2015). The MORPG-based learning system for multiple courses: A case study on computer science curriculum. International Journal of Distance Education Technologies, 13(1), 103-123.

Luo, X. (2009). Quantifying the long-term impact of negative word of mouth on cash flows and stock prices. Marketing Science, 28(1), 148-165.

Marchand, A., \& Hennig-Thurau, T. (2013). Value creation in the video game industry: Industry economics, consumer benefits, and research opportunities. Journal of Interactive Marketing, 27(3), 141-157.

Martin, C., \& Steinkuehler, C. (2010). Collective information literacy in massively multiplayer online games. ELearning and Digital Media, 7(4), 355-365.

McCreery, M. P., Schrader, P. G., \& Krach, S. K. (2011). Navigating massively multiplayer online games: Evaluating 21st century skills for learning within virtual environments. Journal of Educational Computing Research, 44(4), 473-493.

Pauwels, K. (2004). How dynamic consumer response, competitor response, company support, and company inertia shape long-term marketing effectiveness. Marketing Science, 23(4), 598-610.

Song, P., Xue, L., Rai, A., \& Zhang, C. (2018). The ecosystem of software platform: A study of asymmetric crossside network effects and platform governance. MIS Quarterly, 42(1), 121-142.

Sourmelis, T., Ioannou, A., \& Zaphiris, P. (2017). Massively multiplayer online role playing games (MMORPGs) and the 21st century skills: A comprehensive research review from 2010 to 2016. Computers in Human Behavior, 67, 41-48.

Sriram, S., Manchanda, P., Bravo, M. E., Chu, J., Ma, L., Song, M., Shriver, S., \& Subramanian, U. (2015). Platforms: A multiplicity of research opportunities. Marketing Letters, 26(2), 141-152.

Susaeta, H., Jimenez, F., Nussbaum, M., Gajardo, I., Andreu, J. J., \& Villalta, M. (2010). From MMORPG to a classroom multiplayer presential role playing game. Journal of Educational Technology \& Society, 13(3), 257-269.

Tiwana, A. (2014). Platform ecosystems: Aligning architecture, governance, and strategy. Burlington, MA: Morgan Kaufmann of Elsevier.

van der Heijden, H. (2004). User acceptance of hedonic information systems. MIS Quarterly, 28(4), 695-704.

Video game. (2020, April 23). In Wikipedia. https://en.wikipedia.org/wiki/Video_game

Wijman, T. (2018, June 20). Newzoo’s 2018 report: Insights into the $\$ 137.9$ billion global games market. Retrieved from https://newzoo.com/insights/articles/newzoos-2018-report-insights-into-the-137-9-billion-globalgames-market/

Wilbur, K. C. (2008). A two-sided, empirical model of television advertising and viewing markets. Marketing Science, 27(3), 356-378.

Wu, M. L., Richards, K., \& Saw, G. K. (2014). Examining a massive multiplayer online role-playing game as a digital game-based learning platform. Computers in the Schools, 31(1-2), 65-83.

Yee, N. (2006). Motivations for play in online games. CyberPsychology \& Behavior, 9(6), 772-775.

Yu, T. W. (2009). Learning in the virtual world: The pedagogical potentials of massively multiplayer online role playing games. International Education Studies, 2(1), 32-38. 